\title{
A control for comparing schedule-induced drinking with other adjunctive behaviors
}

\author{
J. D. KEEHN \\ York University, Downsview, Ontario, Canada
}

\begin{abstract}
A control for schedule-induced behavior that compares behavioral sequences that occur under continuous and interval food-reinforcement schedules shows that a change from a disorderly to an orderly sequence that occurs with schedule-induced drinking does not occur in the case of schedule-induced bar biting. The control permits study of schedule-regulated behavior whether or not it is excessive.
\end{abstract}

Roper (1981) raised the question of proper controls in the study of schedule-induced drinking, and Timberlake (1982) responded with an argument that the type of control employed in an experiment reveals the experimenter's prior expectations. Most students of scheduleinduced fluid consumption seek reasons for the excessiveness of drinking and employ controls suitable for this framework, but another characteristic of scheduleinduced drinking is the regularity of its occurrence, and for that, control data are seldom reported.

Figure 1 illustrates a possible control in this connection. It shows an animal's eating and drinking performance under continuous reinforcement (crf). Accumulated pellets secured in the session are shown along the abscissa, and the numbers and occasions of licks are marked cumulatively on the ordinate. Several similar graphs have been constructed, all of them showing, as does this one, unpredictable occasions and durations of drinks under crf conditions. Figure 2 shows the same animal's sequences of eating and drinking after four sessions of exposure to a fixed-interval 1-min (FI 1-min) schedule of food reinforcement. Now, drinks follow practically every pellet and drink durations show little variability. Such data are not novel (e.g., Keehn \& Colotla, 1970) but the status of Figure 1 as control information has gone virtually unnoticed in spite of its importance for the possible classification of other induced behaviors with drinking. Roper (1981) argues that crf is a useless control for evaluating excessiveness as a characteristic of schedule-induced activities but ignores its potential in the case of regularity.

Gnawing (Roper, Edwards, \& Crossland, 1983) and bar biting (Keehn, 1976) are other schedule-induced behaviors that occur excessively, but they do not exhibit the same regularity as drinking. Figure 3 , for example, shows bar biting by a rat on its fifth 1 -h session under an FI 1-min food-reinforcement schedule. Under crf,

The author's mailing address is: Department of Psychology, York University, 4700 Keele St., Downsview, Ontario M3J 2R7, Canada. only 10 bar bites occurred while the animal secured 190 reinforcers. The rat bar-bit excessively, but there is no comparison between the erratic biting shown in

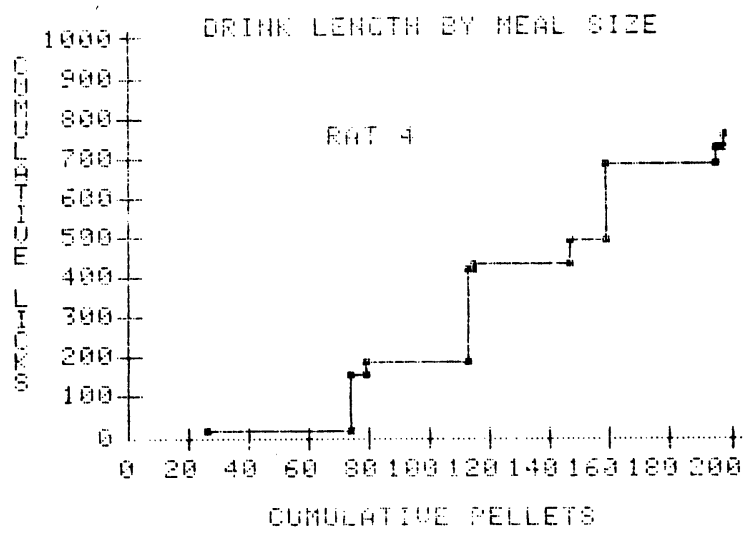

Figure 1. Numbers of pellets before drinks, and the numbers of licks per drink. Horizontal distances between points show the pellets consumed before a drink, and the vertical distances show the size of each drink. The schedule was one of continuous reinforcement.

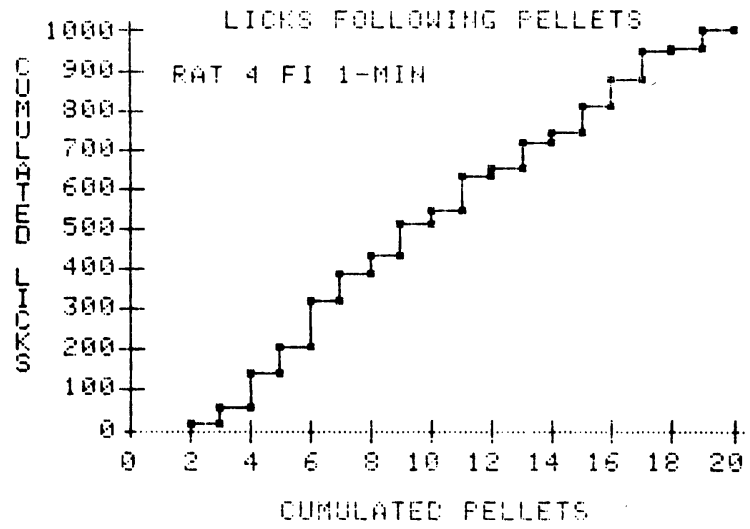

Figure 2. Number of licks following pellets scheduled at fixed 1-min intervals. The regularity of this graph contrasts with the irregularity of Figure 1. 


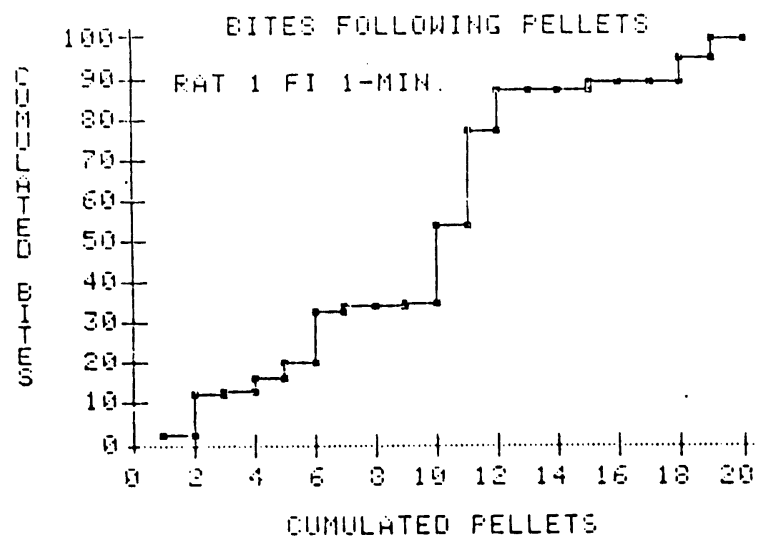

Figure 3. Number of bites following pellets scheduled at fixed 1-min intervals. The irregularity of this graph is comparable to Figure 1 and contrasts with Figure 2. Under continuous reinforcement, almost no biting occurred.

Figure 3 and the orderly drinking that polydipsic rats engage in (cf. Figure 2) under interval schedules of reinforcement. Whatever is common to schedule-induced drinking and other adjunctive behaviors, the orderly nature of its occurrence is a particular, and so far unique, characteristic of adjunctive drinking.

A further advantage of Figure 1 as a control comparison for Figure 2 is that the schedule-induced behavior under investigation need not be taken to excess. Roper (1981) discussed some problems in identifying excess, but these problems do not arise in the case of regularity, in which experimental sessions can terminate before excess occurs. Thus, when drinking is taken as a proto- typical schedule-induced interim activity (Minor \& Coulter, 1982), it is not excessiveness but behavioral sequences (Staddon \& Simmelhag, 1971) for which preexperimental baseline measures are required. In this sense, adjunctive drinking might be better called scheduleregulated behavior, to dissociate it from the excessiveness characteristic of schedule-induced responses.

\section{REFERENCES}

KEEHN, J. D. Schedule-dependent aggression. In E. Ribes-Inestos \& A. Bandura (Eds.), Analysis of delinquency and aggression. Hillsdale, N.J: Erlbaum, 1976.

KeEhN, J. D., \& Colotza, V. A. Prediction and control of schedule-induced drink durations. Psychonomic Science, 1970, 21, 147-148.

Minor, T. R., \& Coulter, X. Associative and postprandial control of schedule-induced drinking: Implications for the study of interim behavior. Animal Learning \& Behavior, 1982, 10, 455-464.

ROPER, T. J. What is meant by the term "schedule-induced," and how general is schedule induction? Animal Learning \& Behavior, 1981, 9, 433-440.

Roper, T. J., Edwards, L., \& Crossland, G. Factors affecting schedule-induced wood-chewing in rats: Percentage and rate of reinforcement, and operant requirement. Animal Learning \& Behavior, 1983, 11, 35-43.

Staddon, J. E. R., \& Simmelhag, V. L. The "superstition" experiment: A re-examination of its implication for the principles of adaptive behavior. Psychological Review, 1971, 78, 3-43.

Timberlake, W. Controls and schedule-induced behavior. Animal Learning \& Behavior, 1982, 10, 535-536.

(Manuscript received for publication September 14, 1983.) 